\title{
Evaluation of enamel pearls by cone-beam computed tomography (CBCT)
}

\author{
Nilgün Akgül ', Fatma Caglayan ${ }^{2}$, Nurhan Durna ${ }^{3}$, Muhammed-Akif Sümbüllü ${ }^{4}$, Hayati-Murat Akgül ${ }^{5}$, \\ Dogan Durna ${ }^{6}$
}

\footnotetext{
${ }^{1}$ Assistant Professor, Department of Restorative Dentistry, Faculty of Dentistry, Atatürk University, Erzurum, Turkey

${ }^{2}$ Assistant Professor, Department of Oral Diagnosis and Oral Radiology, Faculty of Dentistry, Atatürk University, Erzurum, Turkey

${ }^{3}$ Researcher, Numune Hospital, Erzurum, Turkey

${ }^{4}$ Assistant Professor, Department of Oral Diagnosis and Oral Radiology, Faculty of Dentistry, Atatürk University, Erzurum, Turkey

${ }^{5}$ Professor, Department of Oral Diagnosis and Oral Radiology, Faculty of Dentistry, Atatürk University, Erzurum, Turkey

${ }^{6}$ Researcher, Department of Oral Diagnosis and Oral Radiology, Faculty of Dentistry, Atatürk University, Erzurum, Turkey
}

Correspondence:

Department of Oral Diagnosis and Oral Radiology

Faculty of Dentistry, Atatürk University

Erzurum, 25240, Turkey

makgul@atauni.edu.tr

Akgül N, Caglayan F, Durna N, Sümbüllü MA, Akgül HM, Durna D. Evaluation of enamel pearls by cone-beam computed tomography (CBCT). Med Oral Patol Oral Cir Bucal. 2012 Mar 1;17 (2):e218-22.

Received: 12/01/2011 Accepted: 21/05/2011 


\section{Introduction}

Enamel pearls are ectopic deposits of enamel that can be located at the furcation area or on the root surfaces near the cemento-enamel junction. According to Kupietzky and Rozenfarb (1), the enamel pearls was first described in 1842 by Linderer and Linderer as enamel droplets and by Salter in 1874 as enamel nodules. Since then, it has been referred to as an enameloma, enamel globule, enamel knot, and enamel exostoses (1-3).

The etiology of enamel pearls remains obscure. The most common theory is that the pearls develop as a result of a localized developmental activity of a remnant of Hertwig's epithelial root sheat that has remained adherent to the root surface during root development (4). It is believed that these cells differentiate into functioning ameloblasts and produce enamel deposits on the root (1-3).

It varies in size and ranges between 0.3 and $4 \mathrm{~mm}$ in diameter $(5,6)$. Although the majority of enamel pearls are adherents to the external root surface of the tooth, on rare occasions they may be detected within the dentin (internal enamel pearl) $(7,8)$. Structurally, 3 types of enamel pearls have been described $(9,10)$ :

1. The true enamel pearl consisting entirely of enamel.

2. Composite enamel pearl or the enamel-dentin pearl containing a core of tubular dentin.

3. Enamel-dentin-pulp pearl containing a pulp horn, probably extending from the coronal pulp chamber or root canal.

In previous studies, the prevalence of enamel pearls was evaluated by various methods, such as dry skulls, extracted teeth and conventional radiography $(2,3,5)$. To our knowledge, there was not any another study in the literature that evaluated the prevalence of enamel pearls by CBCT in broad study group. The aim of this study was to evaluate the prevalence of enamel pearls according to population, sex and tooth groups on CBCT archive records.

\section{Materials and Methods}

This retrospective study was performed on tomographic images obtained from patients who applied to a variety of dental complaints and needed to examine with CBCT at the Department of Oral Diagnosis and Oral Radiology, Faculty of Dentistry, Atatürk University. Ethical approval was received from the Ethical Committee of Dentistry Faculty.

The volumetric CT used in the study is Newtom FP based on flat-panel (NewTom FPI, QR-DVT-9000, QR srl., Verona, Italy). The exposure parameters used to acquire the images were $110 \mathrm{kVp}, 1-15 \mathrm{~mA}, 17 \mathrm{x} 13$ cylindirical field of view and voxel size of $0.16 \mathrm{~mm}$ and exposure time of 36 seconds. Initially, this study was started with images of 870 patients obtained from archive of CBCT in between 2008-2010. But then, this study was limited to permanent teeth, because the accurate radiographic detection of enamel pearls was both difficult and unreliable in the deciduous dentition and the number of cases was very small. Therefore, patients younger than 15 years at the time of radiographic examination were excluded from the study (102 patients) and was maintained by CBCT images of 768 subjects (430 female and 338 male), with age between 15 and 77 years old.

The cross-sectional examination was performed by single examiner in tomography room. For this purpose, after the volumetric data stored in patient archive were downloaded, presence of enamel pearls was examined by creating new sections in all 3 planes. The study was detailed by creating panoramic images in a digital environment and 3-D images in DICOM format in suspected cases. The results of examination and other clinical data (sex, age) were recorded on a special form designed for this study. To test the reliability of examinations, a random sample of 80 radiographs was re-examined by the same examiner at a later time, and consistency with the previous results was found as $100 \%$. The data were analyzed statistically by means of the computer program SPSS for Windows, and the frequency distribution was calculated for each variable. To compare the prevalence of enamel pearl between male and female subjects, the Pearson chi-squared test was also applied. $\mathrm{P}<0.05$ was considered statistically significant.

\section{Results}

Of the 870 patients, 102 patients were excluded from the study as they were younger than 15 years and CBCT images of 768 subjects was included in the study, which comprised $430(56 \%)$ female and 338 (44\%) male subjects.

Enamel pearls were detected in 36 subjects $(4.69 \%)$, each individual had a single pearl. Enamel pearls were detected in 19 (47.2\%) female and $17(52.8 \%)$ male, and there was no statistically significant association between prevalence of enamel pearls and sex $(\mathrm{x} 2=0.158$, $\mathrm{p}=0.691)($ Table 1).

A total of 15185 teeth was performed cross-sectional examination, of which 6870 were incisors and canines, 3981 premolars, 4334 molars and all of enamel pearls (number of enamel pearls $=36$ ) was detected in molar teeth, with a prevalence of $0.83 \%$ (36 of 4334 molar teeth). Also, the prevalence in total of examined teeth was $0.24 \%$ ( 36 of 15185 teeth).

The distribution of enamel pearls according to molar teeth and jaws is presented in (Table 2). As seen in the table, while enamel pearls was not detected in incisors, canines and premolars, they observed most frequently in maxillary second and third molars, respectively (Fig. $1,2$ and 3$)$. 
Table 1. The distribution of enamel pearls according to sex and statistical comparison.

\begin{tabular}{|c|c|c|c|c|}
\hline & $\begin{array}{c}\text { Number of } \\
\text { Cases }\end{array}$ & $\begin{array}{c}\text { Enamel } \\
\text { Pearls }\end{array}$ & $\mathbf{x}^{\mathbf{2}^{*}}$ & P value** \\
\hline Female & 430 & $19(4.34 \%)$ & 0.158 & 0.691 \\
\hline Male & 338 & $17(5.03 \%)$ & & \\
\hline
\end{tabular}

* Pearson chi-squared test.

**The level of significance ( $\mathrm{P}<0.05$ was considered statistically significant).

Table 2. The distribution of enamel pearls according to molar teeth and jaws.

\begin{tabular}{|l|c|c|c|c|c|c|}
\hline & \multicolumn{2}{|c|}{ Maxillary teeth } & \multicolumn{2}{c|}{ Mandibular teeth } & \multicolumn{2}{c|}{ Total } \\
\cline { 2 - 7 } & $\begin{array}{c}\text { number of } \\
\text { teeth } \mathbf{( \% )}\end{array}$ & $\begin{array}{c}\text { enamel } \\
\text { pearls (\%) }\end{array}$ & $\begin{array}{c}\text { number of } \\
\text { teeth } \mathbf{( \% )}\end{array}$ & $\begin{array}{c}\text { enamel } \\
\text { pearls (\%) }\end{array}$ & $\begin{array}{c}\text { number of } \\
\text { teeth }\end{array}$ & $\begin{array}{c}\text { enamel } \\
\text { pearls (\%) }\end{array}$ \\
\hline First molar & $611(14.1)$ & $4(0.66)$ & $727(16.77)$ & 0 & $1338(30.87)$ & $4(0.30)$ \\
\hline Second molar & $912(21.04)$ & $17(1.86)$ & $1126(25.98)$ & 1 & $2038(47.02)$ & $18(0.88)$ \\
\hline Third molar & $545(12.58)$ & $9(1.65)$ & $413(9.53)$ & $5(1.21)$ & $958(22.11)$ & $14(1.46)$ \\
\hline Total & $2068(47.72)$ & $30(1.45)$ & $2266(52.28)$ & $6(0.26)$ & $4334(100)$ & $36(0.83)$ \\
\hline
\end{tabular}

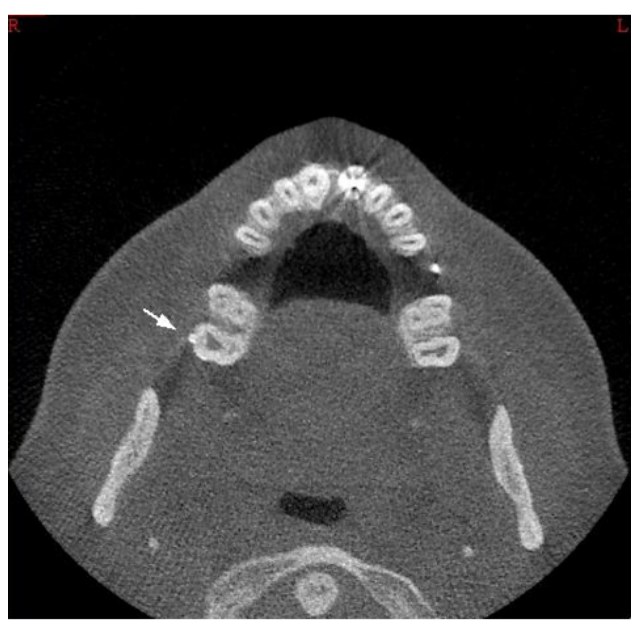

Fig. 1. Axial image of enamel pearl localized at the cemento-enamel junction on the vestibule side of a right maxillary second molar.

\section{Discussion}

The enamel pearls appear as a small globule of enamel, firmly adherent to the tooth's root, which arises from a small group of misplaced ameloblasts (1-3). Pearls also may exhibit hypomineralized areas (4), but generally show a degree and pattern of mineralization, hardness, and chemical context similar to coronal enamel (11-13). Radiographically, the enamel pearls appear as well-defined radiopaque nodules, along the root's surface, comparable in radiodensity to the enamel of the crown $(1,3,10)$. Internal enamel pearls present as welldefined circular areas of radiodensity extending from the enamel-dentin junction into the underlying coronal dentin $(7,8)$. The differential diagnosis should include an isolated piece of calculus, a pulp stone or a composite resin-based cervical restoration $(1,10)$. The differentia- 


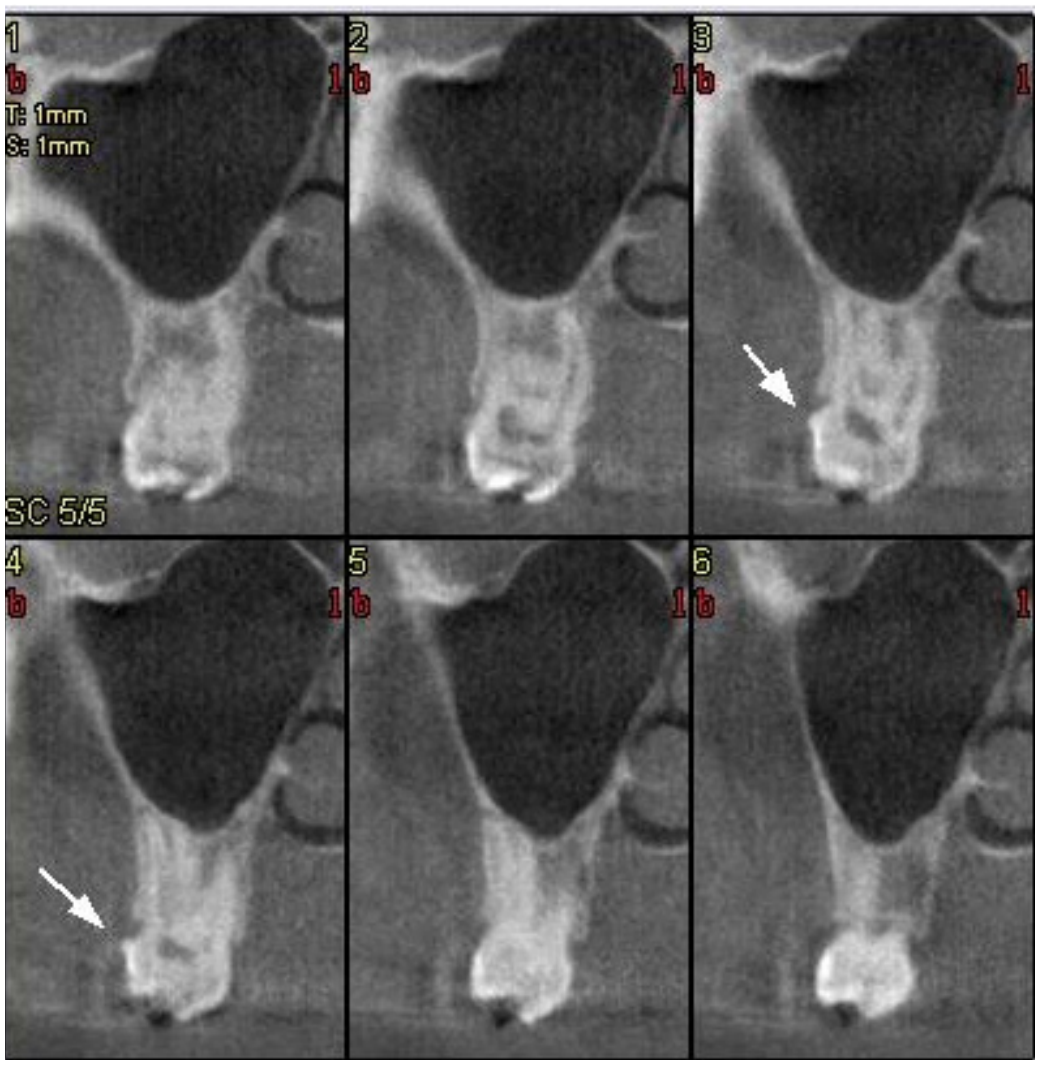

Fig. 2. Sequential cross-sectional view of enamel pearl.

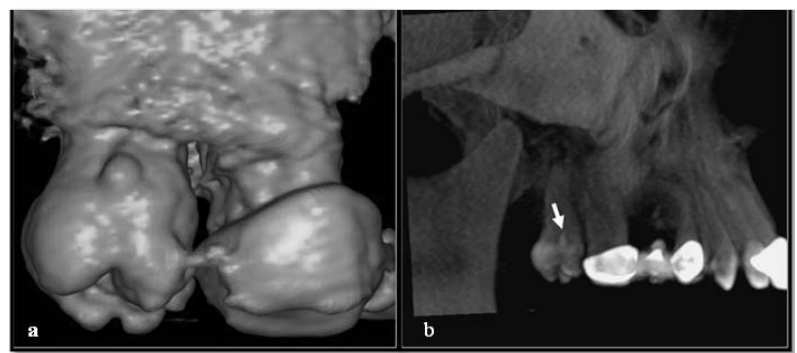

Fig. 3. 3D view of enamel pearl. (a) volume, (b) maximum intensity projection (MIP).

tion between a pulp stone and an enamel pearl can be made by increasing the vertical angle of projection to move the image of the enamel pearl away from the pulp chamber. If the opacity is calculus, it is usually clinically detectable.

Previous researches have been mostly on the external enamel pearls $(2,5,14)$. In our study, thanks to the superiority of CBCT, the presence of both external and internal enamel pearls was investigated. But no tooth with internal enamel pearl was detected in the result of this review.

The enamel pearl is not common. In the researches so far, the prevalence of enamel pearls have been reported to vary between $1.1-9.7 \%$ according to the study population $(2,3,14)$. The variation in the reported prevalence may attribute to ethnic, racial, or national differences $(3,14)$. In the present study, the total prevalence of enamel pearls in examined population was $4.69 \%$, consistent with the studies mentioned above.

Enamel pearls are not common in teeth with a single root. Although there are rare reports of them occurring on roots of maxillary premolars, canines and incisors $(2,14)$, it is generally accepted that enamel pearls are usually found on the root surface of molar teeth $(2,3,5)$. In our study, all of the enamel pearls were also found in molars. 
Also, the prevalence of enamel pearls in molar teeth varies according to the study population, tooth groups and upper and lower jaw. Chrcanovich et al. (2) and Risnes (5) studied extracted teeth and reported that the prevalence of enamel pearls in molars are $1.71 \%$ and $2.28 \%$, respectively. Darwazeh and Hamasha (3), in the survey conducted with conventional radiographs, reported that enamel pearls occurred in $2.32 \%$ of molar teeth. Whereas in our study, the prevalence of enamel pearls was $0.83 \%$ in molar teeth. This rate is quite low compared to the results of previous studies $(3,5)$. This may have been due to methodological differences in addition to population variations. While enamel pearls in the former studies were detected on extracted teeth or with conventional radiographs, our research has been done with CBCT, is a tomographic scanning technology that can scan and acquire a specified volume of the patient head and generate a 3D data set. We think that prevalence was very high in studies performed with conventional radiography, depending on the perception as the enamel pearls of suspicious cases.

As in our study, enamel pearls are usually found most frequently on the roots of the maxillary molars, followed by the roots of the mandibular molars $(1,2,5,14,15)$. However, Darwazeh and Hamasha (3) have radiographically shown that enamel pearls were more common on roots of mandibular molars rather than maxillary molars, in contrast to our finding. Also, in our study, enamel pearls were especially detected most frequently on the maxillary second and third molars, similar to Chrcanovich et al. (2), Risnes (5) and Moskow and Canut (14).

In conclusion, there was no association between the incidence of enamel pearls and gender. Also, all of enamel pearls are found upper and lower molar teeth, especially most commonly in maxillary molars. Maxillary second and third molar teeth are the most common sites, respectively.

\section{References}

References with links to Crossref - DOI

1. Kupietzky A, Rozenfarb N. Enamel pearls in the primary dentition: report of two cases. ASDC J Dent Child. 1993;60:63-6.

2. Chrcanovic BR, Abreu MH, Custódio AL. Prevalence of enamel pearls in teeth from a human teeth bank. J Oral Sci. 2010;52:257-60. 3. Darwazeh A, Hamasha AA. Radiographic evidence of enamel pearls in jordanian dental patients. Oral Surg Oral Med Oral Pathol Oral Radiol Endod. 2000;89:255-8.

4. Risnes S. Ectopic tooth enamel. An SEM study of the structure of enamel in enamel pearls. Adv Dent Res. 1989;3:258-64.

5. Risnes S. The prevalence, location and size of enamel pearls on human molars. Scand J Dent Res. 1974;82:403-12.

6. Goldstein AR. Enamel pearls as a contributing factor in periodontal breakdown. J Am Dent Assoc. 1979;99:210-1.

7. Kaugars GE. Internal enamel pearls: report of case. J Am Dent Assoc. 1983;107:941-3.

8. Mahajan S, Charan CR. An association of external and internal enamel pearls. Indian J Dent Res. 2005;16:17-8.

9. Cavanha AO. Enamel pearls. Oral Surg Oral Med Oral Pathol. 1965;19:373-82.
10. Saini T, Ogunleye A, Levering N, Norton NS, Edwards P. Multiple enamel pearls in two siblings detected by volumetric computed tomography. Dentomaxillofac Radiol. 2008;37:240-4.

11. Gaspersic D. Histogenetic aspects of the composition and structure of human ectopic enamel, studied by scanning electron microscopy. Arch Oral Biol. 1992;37:603-11.

12. Gaspersic D. Enamel microhardness and histological features of composite enamel pearls of different size. J Oral Pathol Med. 1995;24:153-8.

13. Anderson P, Elliott JC, Bose U, Jones SJ. A comparison of the mineral content of enamel and dentin in human premolars and enamel pearls measured by x-ray microtomography. Arch Oral Biol. 1996;41:281-90.

14. Moskow BS, Canut PM. Studies on root enamel (2). Enamel pearls. A review of their morphology, localization, nomenclature, occurence, classification, histogenesis and incidence. J Clin Periodontol. 1990;17:275-81.

15. Risnes S, Segura JJ, Casado A, Jiménez-Rubio A. Enamel pearls and cervical enamel projections on 2 maxillary molars with localized periodontal disease: case report and histologic study. Oral Surg Oral Med Oral Pathol Oral Radiol Endod. 2000;89:493-7. 